\title{
Endothelial inflammation induced by excess glucose is associated with cytosolic glucose 6-phosphate but not increased mitochondrial respiration
}

\author{
I. R. Sweet • M. Gilbert • E. Maloney • \\ D. M. Hockenbery • M. W. Schwartz • F. Kim
}

Received: 18 November 2008 / Accepted: 8 January 2009/Published online: 14 February 2009

(C) Springer-Verlag 2009

\begin{abstract}
Aims/hypothesis Exposure of endothelial cells to high glucose levels suppresses responses to insulin, including induction of endothelial nitric oxide synthase activity, through pro-inflammatory signalling via the inhibitor of nuclear

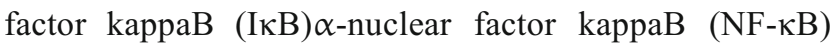
pathway. In the current study, we aimed to identify metabolic responses to glucose excess that mediate endothelial cell inflammation and insulin resistance. Since endothelial cells decrease their oxygen consumption rate (OCR) in response to glucose, we hypothesised that increased mitochondrial function would not mediate these cells' response to excess substrate.

Methods The effects of glycolytic and mitochondrial fuels on metabolic intermediates and end-products of glycolytic and oxidative metabolism, including glucose 6-phosphate (G6P), lactate, $\mathrm{CO}_{2}, \mathrm{NAD}(\mathrm{P}) \mathrm{H}$ and $\mathrm{OCR}$, were measured in cultured human microvascular endothelial cells and correlated with IKB $\alpha$ phosphorylation.

Results In response to increases in glucose concentration from low to physiological levels $(0-5 \mathrm{mmol} / \mathrm{l})$, production of $\mathrm{G} 6 \mathrm{P}$, lactate, $\mathrm{NAD}(\mathrm{P}) \mathrm{H}$ and $\mathrm{CO}_{2}$ each increased as expected, while OCR was sharply reduced. IкB $\alpha$ activation was detected at glucose concentrations $>5 \mathrm{mmol} / \mathrm{l}$, which
\end{abstract}

I. R. Sweet $(\bowtie) \cdot$ M. Gilbert $\cdot$ E. Maloney $\cdot$ M. W. Schwartz $\cdot$

F. Kim

Department of Medicine,

Diabetes and Obesity Center of Excellence,

University of Washington at South Lake Union,

815 Mercer Street, Box 358055, Seattle,

Washington 98195-8055, USA

e-mail: isweet@u.washington.edu

D. M. Hockenbery

Division of Clinical Research,

Fred Hutchinson Cancer Research Center,

Seattle, WA, USA was associated with parallel increases of G6P levels, whereas downstream metabolic pathways were insensitive to excess substrate.

Conclusions/interpretation Phosphorylation of IкB $\alpha$ by excess glucose correlates with increased levels of the glycolytic intermediate G6P, but not with lactate generation or OCR, which are inhibited well below saturation levels at physiological glucose concentrations. These findings suggest that oxidative stress due to increased mitochondrial respiration is unlikely to mediate endothelial inflammation induced by excess glucose and suggests instead the involvement of G6P accumulation in the adverse effects of hyperglycaemia on endothelial cells.

Keywords Glucose 6-phosphate $\cdot$ Human microvascular endothelial cells $\cdot$ Hyperglycaemia $\cdot \operatorname{IKK} \beta \cdot \operatorname{I\kappa B} \alpha$.

Inflammation - Lactate production - Mitochondrial stress .

$\mathrm{NF}-\mathrm{kB} \cdot$ Oxygen consumption

\begin{tabular}{|c|c|}
\hline \multicolumn{2}{|c|}{ Abbreviations } \\
\hline eNOS & Endothelial nitric oxide synthase \\
\hline F6P & Fructose 6-phosphate \\
\hline FCCP & $\begin{array}{l}\text { Carbonyl cyanide 4-(trifluoromethoxy) } \\
\text { phenylhydrazone }\end{array}$ \\
\hline G6P & Glucose 6-phosphate \\
\hline GFAT & Glutamine:fructose-6-phosphate amidotransferase \\
\hline GFP & Green fluorescent protein \\
\hline HK & Hexokinase \\
\hline HMEC & Human microvascular endothelial cells \\
\hline ІкВ & Inhibitor of NF- $\mathrm{KB}$ \\
\hline ICAM & Intercellular adhesion molecule \\
\hline IKK & IкB kinase \\
\hline KRB & Krebs-Ringer bicarbonate solution \\
\hline LPR & Lactate production rate \\
\hline $\mathrm{NF}-\kappa \mathrm{B}$ & Nuclear factor kappaB \\
\hline OCR & Oxygen consumption rate \\
\hline
\end{tabular}


PFK Phosphofructokinase

ROS Reactive oxygen species

TCA Tricarboxylic acid test this prediction, the current work was undertaken to determine how metabolic fluxes in primary endothelial cells respond to glucose concentrations above the physiological range, and to relate metabolic flux to glucose-induced inflammation.

\section{Methods}

Chronically high levels of blood glucose and NEFA, as seen in type 2 diabetes and obesity, are associated with increased risk of cardiovascular disease. In endothelial cells, excess NEFA activates the pro-inflammatory IKK $\beta-$ nuclear factor kappaB $(\mathrm{NF}-\kappa \mathrm{B})$ pathway (where IKK $\beta$ is a kinase for IKB), via a mechanism that involves Toll-like receptor 4 signalling, and this effect in turn causes cellular insulin resistance and impaired nitric oxide production [1]. Exposure of endothelial cells to excess glucose also induces inflammation and insulin resistance [2-4], but the underlying mechanisms remain to be established. Most current hypotheses are based on increased glucose use by various metabolic pathways [5] leading to accumulation of proinflammatory intermediates or by-products (such as reactive oxygen species [ROS]). Candidate metabolic pathways include glycolysis, the pentose shunt, hexosamine biosynthesis, the tricarboxylic acid (TCA) cycle, and the coupled mitochondrial processes of electron transport and oxidative phosphorylation. Of these pathways, increased (or overburdened) mitochondrial respiration has been the most accepted model of generation of oxidative stress [6]. However, a critical test of this hypothesis, the demonstration that as a function of glucose concentration, glucose use correlates with the known effects of hyperglycaemia on signal transduction pathways and pro-inflammatory responses in endothelial cells, has not been carried out.

In many cell types, control of glucose use depends on the efficiency of glucose transport relative to hexokinase (HK) activity. In endothelial cells, glucose transport uptake into endothelial cells involves facilitated diffusion through the glucose transporter GLUT1 [7] and is insensitive to insulin [8]. Endothelial cells express HK I [9], which has a $K_{\mathrm{m}}$ for glucose $(0.05 \mathrm{mmol} / 1$ [10]) that is lower than that for GLUT1 [11]. Thus, the rate of glucose use can be expected to plateau at low-glucose concentrations unless the $V_{\max }$ for GLUT1 is much lower than that for HK I, a ratio that has not been determined. Of great significance for this study, endothelial cells are highly glycolytic and exhibit decreased oxygen consumption rate (OCR) in the presence of glucose (the Crabtree effect) [12]. The implication of glucose's inhibition of OCR is that mitochondrial energetics at physiological glucose would be sub-maximal and this does not support the notion that mitochondria are in an overburdened state in the face of hyperglycaemia. In order to
Chemicals Krebs-Ringer bicarbonate solution (KRB) supplemented with $20 \mathrm{mmol} / \mathrm{l}$ HEPES/NaHEPES (Roche, Indianapolis, IN, USA) and $0.1 \%$ (wt/vol.) BSA (Serological Corporation, Norcross, GA, USA) was used for the perifusion analysis and was made up as previously described [13]. Antimycin A, KCN, and carbonyl cyanide 4-(trifluoromethoxy)phenylhydrazone (FCCP), were purchased from Sigma-Aldrich (St Louis, MO, USA). $\left[{ }^{14} \mathrm{C}\right]$ Glucose was purchased from Perkin Elmer (Waltham, MA, USA). Antibodies (anti-phospho-inhibitor of NF- $\mathrm{KB}$ $[\mathrm{I \kappa B}] \alpha$, anti-phospho-Akt and anti-phospho-endothelial nitric oxide synthase [eNOS], and total Akt antibodies), were obtained from Cell Signaling (Beverly, MA, USA); anti-eNOS was obtained from Transduction Laboratories (Becton Dickinson, Franklin Lakes, NJ, USA).

Culture of human microvascular endothelial cells (HMEC) HMEC (a generous gift from F. J. Candal and T. Lawley, Emory University, Atlanta, GA, USA) were cultured in RPMI 1640 supplemented with 10\% (vol./vol.) FBS (Hyclone Laboratories, Logan, UT, USA) and $12 \mathrm{mg} / \mathrm{ml}$ of bovine brain extract (Clonetics, Walkersville, MD, USA), L-glutamine $(2 \mathrm{mmol} / \mathrm{l})$, sodium pyruvate $(1 \mathrm{mmol} / \mathrm{l})$ and non-essential amino acids in the presence of penicillin $(100 \mathrm{U} / \mathrm{ml})$ and maintained at $37^{\circ} \mathrm{C}$ in $5 \% \mathrm{CO}_{2}$.

Western analysis of I $\mathrm{K} B \alpha$, a marker of IKK $\beta$ activity, and assays for other markers of inflammation Prior to initiation of these experiments, HMEC were cultured in DMEM containing $0.1 \%$ (vol./vol.) FBS overnight and then for $3 \mathrm{~h}$ in EBM (Clonetics). DMEM and EBM were supplemented with either 5 or $25 \mathrm{mmol} / \mathrm{l}$ glucose for the indicated time intervals. Western blots were performed using $40 \mu \mathrm{g}$ total protein for each condition and experiment. SDS gel electrophoresis was performed using either a $9 \%$ (wt/vol.) gel, or $4 \%$ by $20 \%$ gradient gel, transferred onto nitrocellulose and probed with an anti-phospho-IкB $\alpha$ antibody. The phosphorylation level of $I \kappa B \alpha$ is an indirect measure of IKK $\beta$ activity as it has been found that $\operatorname{IKK} \beta$ is the primary kinase acting upon $\mathrm{I} \kappa \mathrm{B} \alpha$ in the presence of excess glucose [14].

IL-6 levels in supernatant fractions from treated HMEC were measured by ELISA, and intercellular adhesion molecule (ICAM) protein levels were determined by 
western blot analysis under non-reduced conditions using a kit and an anti-human ICAM antibody, respectively, from R\&D Systems (Minneapolis, MN, USA). Total ICAM, eNOS, phospho-eNOS, phospho-Akt and phospho-IкB $\alpha$ levels were assessed using western blot analysis and were quantified using Image $J$ software (NIH). NF- $\kappa B$ activity was determined using a Trans AM NF- $\kappa B$ p65 Kit (Active Motif, Carlsbad, CA, USA).

Measurement of OCR and lactate production rate (LPR) A flow culture system was used that concomitantly measures OCR while collecting outflow fractions for subsequent measurement of lactate (described previously [15-17]). Oxygen tension was measured by detecting the phosphorescence lifetime (Tau Theta, Boulder, CO, USA) of an oxygen-sensitive dye that was painted on the inside of the perifusion chamber [13]. Lactate was measured using a kit purchased from Invitrogen (Amplex Red Glucose/Glucose Oxidase Assay Kit, Carlsbad, CA, USA) per manufacturer's instruction except that lactate oxidase was substituted for glucose oxidase. OCR and LPR were calculated as the product of the flow rate (approximately $150 \mu \mathrm{l} / \mathrm{min}$ ) and the difference between inflow and outflow levels of oxygen or lactate, respectively. Inflow oxygen tension was determined at the end of each experiment by inhibiting cellular respiration with antimycin $\mathrm{A}[15,18]$.

Imaging and quantification of $N A D(P) H$ One hour prior to these experiments, HMEC were trypsinised, plated onto glass cover slips, and maintained in $5 \% \mathrm{CO}_{2}$ at $37^{\circ} \mathrm{C}$. The cover slips were then placed into a temperature-controlled perifusion dish (Bioptechs, Butler, PA, USA) that was mounted onto the stage of a Nikon Eclipse TE-200 inverted microscope (Melville, NY, USA), and KRB was pumped through the dish at a flow rate of $150 \mu \mathrm{l} / \mathrm{min}$. NAD(P)H autofluorescence was detected at $460 \mathrm{~nm}$ by a Cool Snap EZ camera (Photometrics, Tucson, AZ, USA) during excitation at $360 \mathrm{~nm}$. At the end of the experiments, the steady-state fluorescence in the presence of $\mathrm{KCN}$ and subsequently FCCP was measured (for 20 and $60 \mathrm{~min}$, respectively). The normalised fluorescence of $\mathrm{NAD}(\mathrm{P}) \mathrm{H}$ was then calculated as:

reduced NADH $(\%)=100 \times \frac{\mathrm{RFU}_{\text {test }}-\mathrm{RFU}_{\mathrm{FCCP}}}{\mathrm{RFU}_{\mathrm{KCN}}-\mathrm{RFU}_{\mathrm{FCCP}}}$

where RFU is relative fluorescence units, and $\mathrm{RFU}_{\mathrm{FCCP}}$ and $\mathrm{RFU}_{\mathrm{KCN}}$ equalled the average of the final ten time-points at which each agent was present.

Measurement of $\mathrm{CO}_{2}$ production $\mathrm{CO}_{2}$ production was quantified radiometrically based on the production of ${ }^{14} \mathrm{CO}_{2}$ from $\left[\mathrm{U}_{-}{ }^{14} \mathrm{C}\right]$ glucose. HMEC were trypsinised and $5 \times 10^{5}$ cells were placed in $12 \mathrm{~mm} \times 75 \mathrm{~mm}$ test tubes containing
$0.5 \mathrm{ml} \mathrm{KRB}$ with different concentrations of glucose at $37^{\circ} \mathrm{C}$ for $60 \mathrm{~min}$. A piece of Whatman filter paper was suspended in a plastic cup above the cell/buffer solution and the vials were stoppered and gassed with $5 \% \mathrm{CO}_{2} /$ balance air. The tubes were then stoppered and $74 \mathrm{kBq}$ of $\left[\mathrm{U}^{-14} \mathrm{C}\right]$ glucose was injected, and the cells were incubated for exactly $60 \mathrm{~min}$. Subsequently, $\mathrm{CO}_{2}$ production was determined as previously described [19].

Measurement of glucose 6-phosphate (G6P) Cells were harvested and incubated in $12 \mathrm{~mm} \times 75 \mathrm{~mm}$ test tubes $\left(2 \times 10^{6}\right.$ in $\left.0.2 \mathrm{ml} \mathrm{KRB}\right)$ containing various concentrations of glucose or pyruvate as indicated. At precise times, $0.16 \mathrm{ml}$ cold $0.6 \mathrm{~mol} / \mathrm{l}$ perchloric acid was added, and extracts were prepared as carried out previously [20]. G6P in the extracts was measured by fluorometric detection of NADPH after incubation with NADP and G6P dehydrogenase (SigmaAldrich) as described [21].

\section{Results}

Effect of high glucose on I $\mathrm{\kappa} B \alpha$ phosphorylation and endothelial inflammation To determine the time-course of inflammation induced by excess glucose, the concentration of glucose exposed to HMEC was changed from 5 to $25 \mathrm{mmol} / 1$ glucose media for time intervals ranging from 0 to $18 \mathrm{~h}$ (Fig. 1). Exposure to $25 \mathrm{mmol} / \mathrm{l}$ glucose increased levels of phospho-IKB $\alpha$, a measure of IKK $\beta$ activity (Fig. 1a). This is consistent with previous results where $25 \mathrm{mmol} / \mathrm{l}$ glucose, but not mannitol, led to an increase in phospho-IкB $\alpha$ [2]. A readily detectable increase of phosphoIкB $\alpha$ levels occurred within $60 \mathrm{~min}$, and remained elevated after $18 \mathrm{~h}$. In contrast, total $\operatorname{IKK} \beta$, as assessed by western blots, did not change. Glucose-mediated increases in NF- $\mathrm{kB}$ dependent signalling (IL-6 and ICAM) occurred after $3 \mathrm{~h}$ of exposure to $25 \mathrm{mmol} / \mathrm{l}$ glucose (Fig. $1 \mathrm{~b}, \mathrm{c}$ ). To confirm increased NF- $\mathrm{kB}$ activity directly, HMEC lysates treated with $25 \mathrm{mmol} / \mathrm{l}$ glucose for 1 and $3 \mathrm{~h}$ were analysed for NF$\kappa \mathrm{B}$ activity (Fig. 1d). Consistent with its role as a key trigger of inflammation, I $\mathrm{I} \mathrm{B} \alpha$ activation preceded the increases measured in the other three proteins.

Effect of $N F-\kappa B$ signalling on endothelial insulin signalling In order to assess the impact of NF- $\mathrm{\kappa B}$ on endothelial insulin signalling, we next tested HMEC in which NF- $\kappa B$ signalling was attenuated. HMEC transduced with a phosphorylationresistant IאB $\alpha$ (serine 32,36/Ala) [1] or green fluorescent protein (GFP) were treated with 5 or $25 \mathrm{mmol} / \mathrm{l}$ glucose for $12 \mathrm{~h}$, followed by stimulation with $100 \mathrm{nmol} / 1$ insulin for 15 min (Fig. 2). Insulin-mediated Akt and eNOS phosphorylation was assessed by western blot analysis. As expected, in GFP-transduced cells high glucose was associated with 
a
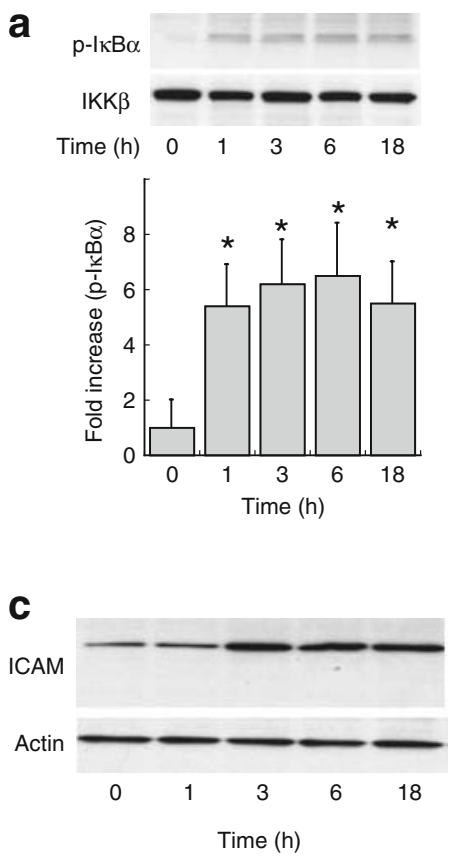

b

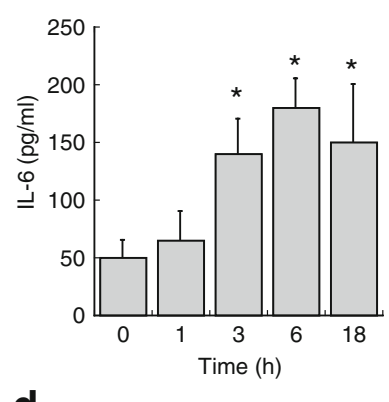

d

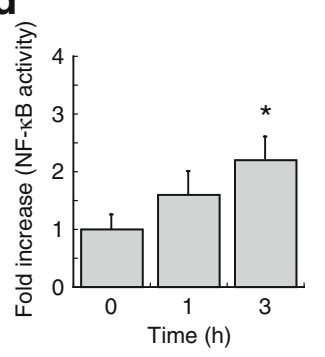

Fig. 1 The temporal effect of glucose on activation of NF- $\kappa B$ signalling. HMEC were cultured for the denoted time in the presence of various concentrations of glucose. Densitometry was performed, and after normalising the data for total $\operatorname{IKK} \beta$, the fold increase over the $5 \mathrm{mmol} / \mathrm{l}$ glucose control was calculated $(n=3)$. a Levels of phospho (p)-IкB $\alpha$ determined by western blotting in lysates of HMEC treated with $25 \mathrm{mmol} / \mathrm{l}$ glucose for time periods between 1 and $18 \mathrm{~h}$. b IL- 6 levels in response to $25 \mathrm{mmol} / 1$ glucose as measured by ELISA. c Representative western blots $(n=3)$ of ICAM and actin protein levels in response to $25 \mathrm{mmol} / \mathrm{l}$ glucose. $\mathbf{d ~ N F - \kappa B}$ activity in response to $25 \mathrm{mmol} / 1$ glucose. Comparisons between groups of treatments were made by ANOVA, followed by a Bonferroni post hoc test when significance was indicated. ( ${ }^{*} p<0.05$ considered significant)

impaired insulin-mediated phospho-Akt and phospho-eNOS, whereas in HMEC, with attenuated NF- $\mathrm{kB}$ signalling, this effect was blocked (Fig. 2).

\section{Continuous measurement of HMEC metabolism using a flow} culture system A flow culture system originally designed for pancreatic islets was adapted for analysis of HMEC metabolism in response to substrate availability $[16,17]$. As in many proliferative cells, OCR by HMEC measured in $20 \mathrm{mmol} / 1$ glucose was approximately $50 \%$ lower than observed in media without glucose (the Crabtree effect) recapitulating the observation that in the presence of glucose, mitochondrial activity is sub-maximal (Fig. 3). Repeated changes in perifusate glucose concentration produced virtually identical results, indicating that the decline in OCR was not due to irreversible cell injury or death.

Lack of sensitivity of OCR and LPR to changes in glucose between 5 and $25 \mathrm{mmol} / \mathrm{l}$ Having demonstrated the usefulness of the flow culture system to study HMEC metabolism,

a

b

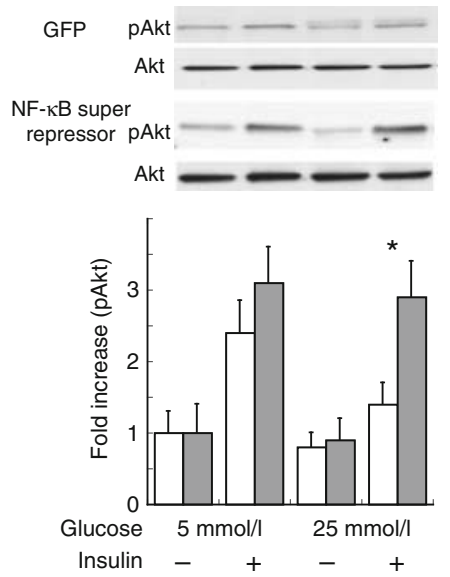

Fig. 2 The effect of NF- $\kappa B$ on insulin signalling in endothelial cells exposed to $25 \mathrm{mmol} / \mathrm{l}$ glucose. HMEC transduced with either a GFP construct (white bars) or phosphorylation-resistant $\mathrm{I} \kappa \mathrm{B} \alpha(\mathrm{NF}-\kappa \mathrm{B}$ super repressor) construct (grey bars) were treated with vehicle or insulin $(100 \mathrm{nmol} / \mathrm{l})$ for $15 \mathrm{~min}$ at the indicated concentrations of glucose. a Insulin-mediated phosphorylation (p) of Akt as measured by western blot was quantified and normalised to total Akt levels for three independent experiments. Fold increase over the low-glucose $(5 \mathrm{mmol} / \mathrm{l})$ vehicle condition was calculated for the GFP-transduced HMEC and $\mathrm{NF}-\kappa \mathrm{B}$ super transduced HMEC $\left({ }^{*} p<0.05\right)$. b Insulin-mediated phospho-eNOS (peNOS) as measured by western blotting was quantified and normalised to total eNOS

we next considered the distribution of metabolic responses to substrate with step changes in glucose concentration from 0 to 5 and from 5 to $25 \mathrm{mmol} / \mathrm{l}$. Increased LPR accompanied the reduction in OCR induced by elevated glucose concentrations (Fig. 4). Statistical analysis was carried out on the steady-state values of LPR, OCR and $\mathrm{NAD}(\mathrm{P}) \mathrm{H}$ at 5 and $25 \mathrm{mmol} / \mathrm{l}$ glucose (calculated as the average of the final

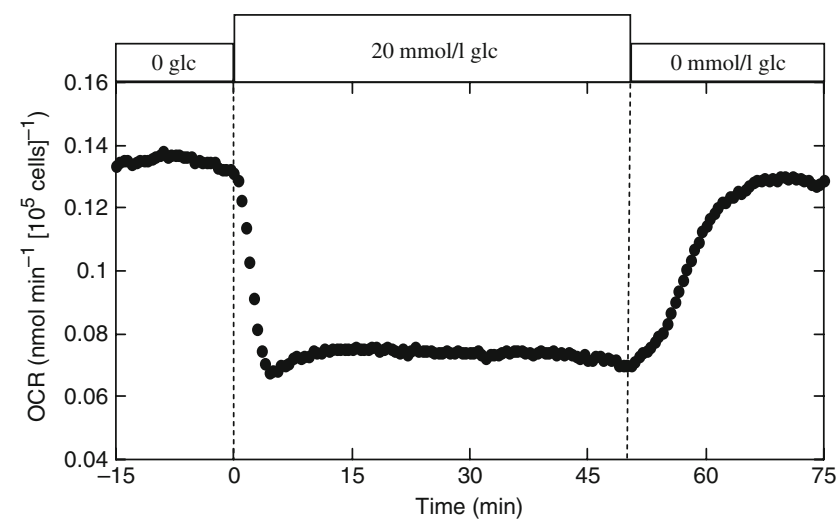

Fig. 3 Temporal changes in OCR in response to the addition and removal of $20 \mathrm{mmol} / \mathrm{l}$ glucose (glc). HMEC were loaded into a perifusion system (two chambers were run in parallel with $4 \times 10^{6}$ cells loaded into each) and allowed to equilibrate for $90 \mathrm{~min}$ in the presence of $20 \mathrm{mmol} / 1$ glucose. The glucose was then washed out or added to the inflow media as indicated. Because of mixing within the chamber, the temporal resolution of the measurements is limited to about $5 \mathrm{~min}$. Data points are the average of two data sets collected in parallel 

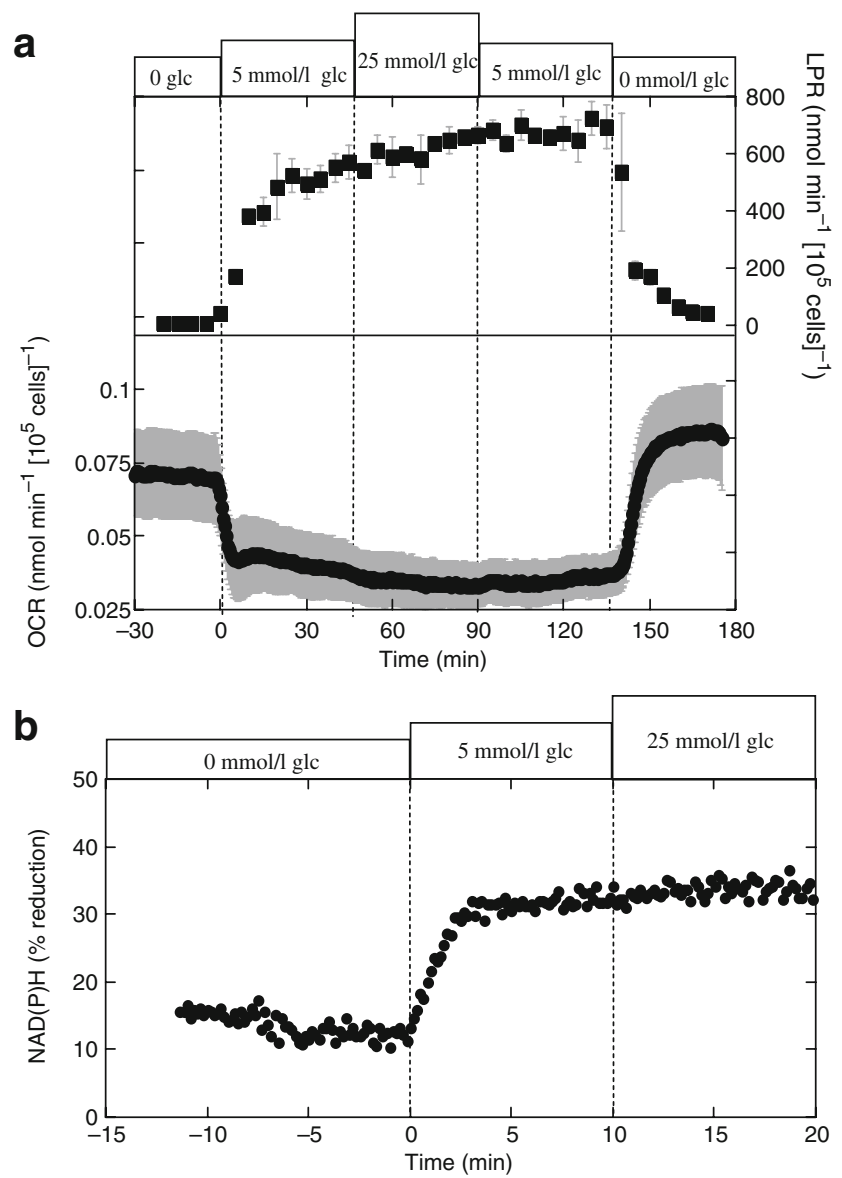

Fig. 4 Effect of glucose on OCR and LPR (a) and NAD(P)H (b) by HMEC. a Experiments were carried out as described in Fig. 3, except that the protocol involved testing the effect of 0,5 and $25 \mathrm{mmol} / 1$ glucose (glc), and data represent the average \pm SEM of separate perifusions. OCR decreased and LPR increased in response to $5 \mathrm{mmol} / \mathrm{l}$ glucose, but switching between 5 and $25 \mathrm{mmol} / \mathrm{l}$ glucose appeared to have little effect. b $\mathrm{NAD}(\mathrm{P}) \mathrm{H}$ was measured in response to sequential increases in glucose to 5 and $25 \mathrm{mmol} / \mathrm{l}$. Data shown are averages of two separate perifusions, where each kinetic profile was an average time-course of three cells. $\mathrm{NAD}(\mathrm{P}) \mathrm{H}$ was normalised relative to $100 \%$ (in the presence of $\mathrm{KCN}$ ) and $0 \%$ (in the presence of FCCP) as described in the 'Methods' section. Statistical analysis was carried out on the steady-state values at 5 and $25 \mathrm{mmol} / 1$ glucose (calculated as the average of the final $15 \mathrm{~min}$ of data obtained during each concentration of glucose) using a Student's $t$ test with paired data calculated with Kaleidagraph (Synergy Software, Reading, PA, USA). The differences in OCR, LPR and $\mathrm{NAD}(\mathrm{P}) \mathrm{H}$ between the two conditions were not significant

15 min of data obtained during each concentration of glucose). Using a Student's $t$ test, with paired data, the difference between the two conditions for the three variables was not significant. Since neither LPR nor OCR was significantly affected by increasing glucose levels from 5 to $25 \mathrm{mmol} / \mathrm{l}$, these results demonstrated that the increment from 0 to $5 \mathrm{mmol} / \mathrm{l}$ glucose accounted for nearly all of the Crabtree effect (increased LPR and $\mathrm{NAD}(\mathrm{P}) \mathrm{H}$, and decreased $\mathrm{OCR}$ ). Thus, increasing glucose levels from normal $(5 \mathrm{mmol} / \mathrm{l})$ to values seen in uncontrolled diabetes $(25 \mathrm{mmol} / \mathrm{l})$ leads to rapid $\operatorname{IKK} \beta$ activation in endothelial cells despite no change of LPR or OCR, suggesting that the mechanism linking glucose excess to cellular inflammation is independent of both lactate production and mitochondrial substrate oxidation.

Dose-dependent effects of glucose on G6P, LPR, $\mathrm{CO}_{2}$ production, $N A D(P) H$ and $O C R$ To identify glucose metabolic pathways in HMEC that respond to glucose concentrations $>5 \mathrm{mmol} / \mathrm{l}$, we measured markers of glucose phosphorylation (G6P), glycolysis (LPR), mitochondrial activity $(\mathrm{NAD}(\mathrm{P}) \mathrm{H}$ and $\mathrm{OCR})$ and cellular glucose use $\left(\mathrm{CO}_{2}\right.$ production rate) as a function of glucose concentration ranging from 0 to $25 \mathrm{mmol} / \mathrm{l}$ (Fig. 5). The full range of glucose concentrations were tested in order to provide positive controls for any negative findings occurring between 5 and $25 \mathrm{mmol} / \mathrm{l}$ glucose. Maximal values of OCR were clearly achieved at glucose concentrations $<1 \mathrm{mmol} / 1$ glucose, and OCR, NAD(P)H and LPR were all insensitive to glucose concentrations $>5 \mathrm{mmol} / \mathrm{l}$. In contrast, intracellular G6P levels increased by $37 \%$ in HMEC as glucose increased from 5 to $25 \mathrm{mmol} / \mathrm{l}$, and $\mathrm{CO}_{2}$ production increased by $32 \%$ (Fig. 5e, f). Thus, complete glycolytic or oxidative metabolism of glucose concentration required for ATP production is not sensitive to glucose supply at concentrations $>5 \mathrm{mmol} / \mathrm{l}$, whereas metabolic conversion to G6P (the initial step in glycolysis) tracks with $\operatorname{IKK} \beta$ activity (Fig. 1).

Effects of pyruvate on $I \kappa B \alpha, G 6 P$ and $O C R$ To further test the hypothesis that increased mitochondrial oxidative phosphorylation is not a driving force for glucose-induced $\mathrm{I} \kappa \mathrm{B} \alpha$ activation, as suggested by the above analysis, we next investigated the effect of increasing respiration through addition of a mitochondrial fuel such as pyruvate. As expected, we observed that media containing $10 \mathrm{mmol} / \mathrm{l}$ pyruvate without glucose robustly increased HMEC OCR (Fig. 6), but had no effect on IкB $\alpha$ activity (Fig. 7). As predicted, therefore, increased mitochondrial substrate oxidation is not a stimulus for cellular inflammation in HMEC. Furthermore, in the absence of glucose, G6P was barely detectable in either the presence or absence of pyruvate, raising the possibility that cellular accumulation of G6P is required for $\mathrm{I} \kappa \mathrm{B} \alpha$ activation.

To test this hypothesis, we investigated whether conditions that raise G6P can stimulate I $\mathrm{B} \alpha$ even at glucose concentrations below those that trigger a cellular inflammatory response. Pyruvate, as a respiratory substrate, increases intracellular levels of both citrate and ATP, two well known inhibitors of the glycolytic enzyme phosphofructokinase (PFK) [22]. In the presence of glucose substrate, this feedback inhibition can be anticipated to increase levels of the upstream metabolite, G6P, and therefore pyruvate could be used as a 


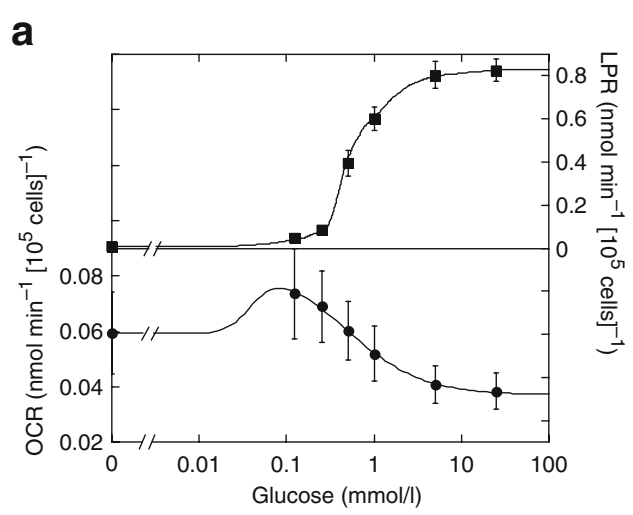

b

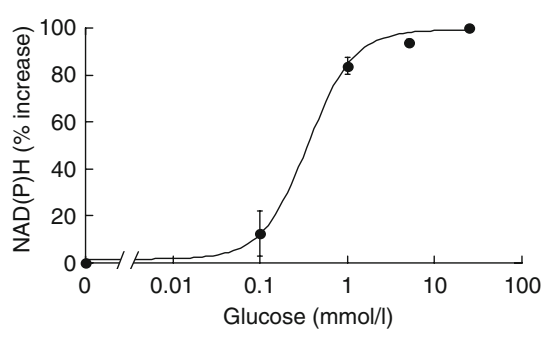

f

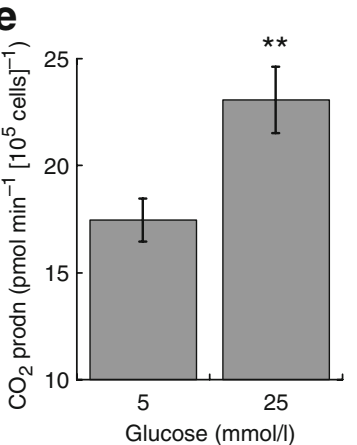

C

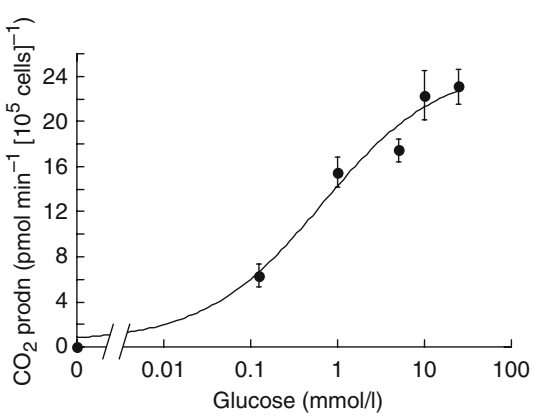

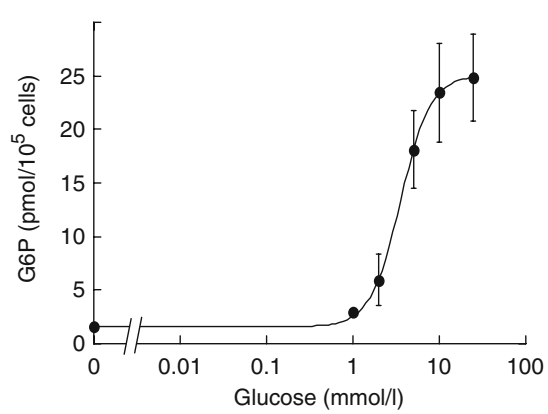

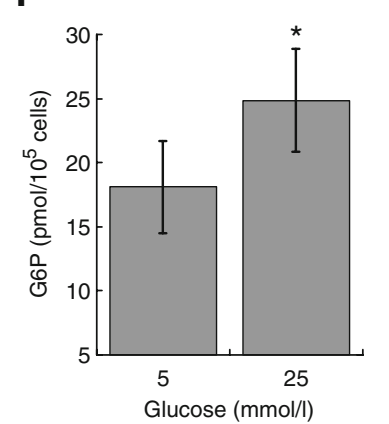

Fig. 5 Glucose dose-responses of LPR and OCR (a), NAD(P)H (b), $\mathrm{CO}_{2}$ production (c) and $\mathrm{G} 6 \mathrm{P}(\mathbf{d})$. LPR, OCR and $\mathrm{NAD}(\mathrm{P}) \mathrm{H}$ values were measured using flow systems and are steady-state values averaged from 15 to $30 \mathrm{~min}$ after the change in glucose concentration. $\mathrm{CO}_{2}$ production was measured under static conditions and is an integrated response over $45 \mathrm{~min}$. G6P values were single time-point measurements obtained $30 \mathrm{~min}$ after the change in glucose. Each data point is an average of four separate experiments, except for the NAD

tool to test the relationship between G6P and inflammation. The addition of $1 \mathrm{mmol} / \mathrm{l}$ pyruvate did not affect G6P in HMEC (data not shown). However, as expected, HMEC in the presence of $10 \mathrm{mmol} / \mathrm{l}$ pyruvate and a physiological glucose concentration ( $5 \mathrm{mmol} / \mathrm{l})$ exhibited increased OCR and G6P compared with the single substrates (Fig. 8). Furthermore, I $\kappa \mathrm{B} \alpha$ activation was observed under these conditions (Fig. 7). Taken together, these results demonstrate that glucose-induced $\mathrm{I} \kappa \mathrm{B} \alpha$ activation is independent of substrate-induced oxidative phosphorylation or glycolytic flux, but is consistently correlated with increased G6P. Glucose excess $(25 \mathrm{mmol} / \mathrm{l}$ glucose $)$ or total substrate excess (5 mmol/l glucose $+10 \mathrm{mmol} / \mathrm{l}$ pyruvate) may therefore promote pro-inflammatory signalling through a common intermediate, G6P (Table 1).

\section{Discussion}

Excess substrate and pro-inflammatory signalling IKK $\beta$ phosphorylates $\mathrm{I} \kappa \mathrm{B}$ proteins in the classic pathway of
(P)H data $(n=3)$, and the $\mathrm{CO}_{2}$ data $(n=5)$ and error bars are \pm SEM. Statistical significance of differences between the values of each variable at 5 and $25 \mathrm{mmol} / \mathrm{l}$ glucose was determined using a paired Student's $t$ test calculated with Kaleidagraph (Synergy Software, Reading, PA, USA). Only the differences between 5 and $25 \mathrm{mmol} / \mathrm{l}$ glucose in $\mathrm{G} 6 \mathrm{P}$ and $\mathrm{CO}_{2}$ production were significant, as shown by the bar graphs $(\mathbf{e}, \mathbf{f})\left({ }^{*} p<0.05\right.$ and $\left.{ }^{* *} p<0.01\right)$. prodn, production

$\mathrm{NF}-\kappa \mathrm{B}$ activation, whereby ubiquitin-mediated degradation of I $\mathrm{B}$ allows nuclear translocation of NF- $\kappa \mathrm{B}$, where it functions as a key transcriptional regulator of cellular inflammatory mediators. Among endothelial genes transactivated by NF- $\kappa \mathrm{B}$ are those involved in inflammation (for IL-1, TNF- $\alpha$ and IL-6) and leukocyte adhesion (for E-selectin, ICAM-1 and vascular cell adhesion molecule-1) [6]. Supraphysiological levels of glucose induce rapid and sustained NF- $\kappa \mathrm{B}$ activation in HMEC and bovine aortic endothelial cells in vitro $[2,3]$, and these effects are both necessary and sufficient to cause insulin resistance and reduce nitric oxide production by these cells. In the present study we recapitulated the findings that glucose increases

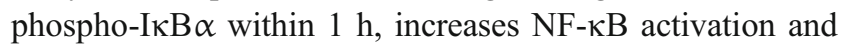
$\mathrm{NF}-\kappa \mathrm{B}-$ dependent gene transcription within $3 \mathrm{~h}$ of exposure to $25 \mathrm{mmol} / \mathrm{l}$ glucose, and impairs endothelial cell insulin signalling. Subsequently, we endeavoured to understand the mechanism mediating these effects of glucose excess.

One mechanism proposed to mediate glucose-sensing in endothelial cells involves mitochondrial ROS generation as a consequence of increased metabolic supply of pyruvate 


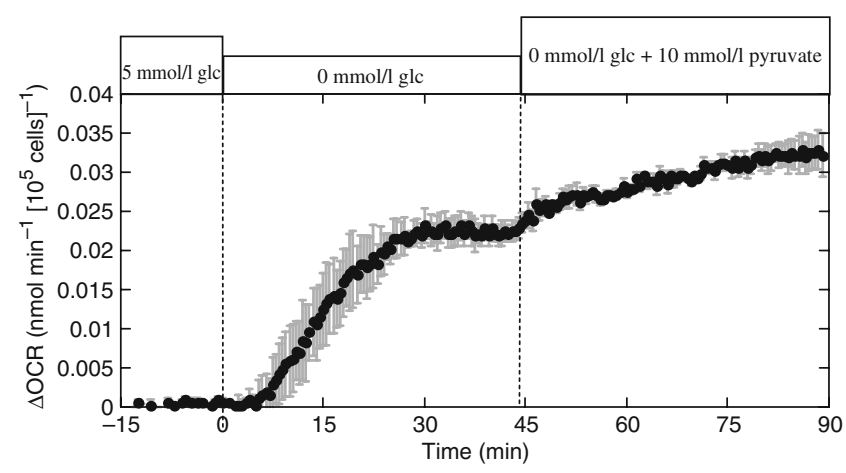

Fig. 6 Effect of pyruvate on OCR by HMEC in the absence of glucose. As shown, the protocol entailed washing out the glucose, and after $30 \mathrm{~min}$, assessing the effect of $10 \mathrm{mmol} / \mathrm{l}$ pyruvate on OCR. LPR was also measured, but lactate levels were below the detection limit of the assay. In order to calculate error bars relative to the change in OCR, change in OCR ( $\triangle \mathrm{OCR})$ was calculated as the average of three separate perifusions, where individual time-points were normalised by subtracting the baseline OCR at $5 \mathrm{mmol} / 1$ glucose (averaged from -15 to $0 \mathrm{~min}$ )

and reducing equivalents for mitochondrial respiration [6]. Our findings, however, are inconsistent with this mechanism of glucose sensing. Specifically, raising glucose to concentrations seen in uncontrolled diabetes $(25 \mathrm{mmol} / \mathrm{l})$ did not result in changes in cellular $\mathrm{NAD}(\mathrm{P}) \mathrm{H}$ or $\mathrm{OCR}$, and at concentrations $>5 \mathrm{mmol} / \mathrm{l}$ glucose, OCR is $<50 \%$ of maximal. Both of these results suggest that increased mitochondrial substrate flux does not mediate cellular inflammatory responses to high glucose. In contrast, both G6P levels and I $\mathrm{I} B \alpha$ phosphorylation increased upon exposure to excess substrate (high glucose or low glucose+ pyruvate). Thus rapid phosphorylation of IкB $\alpha$ in response

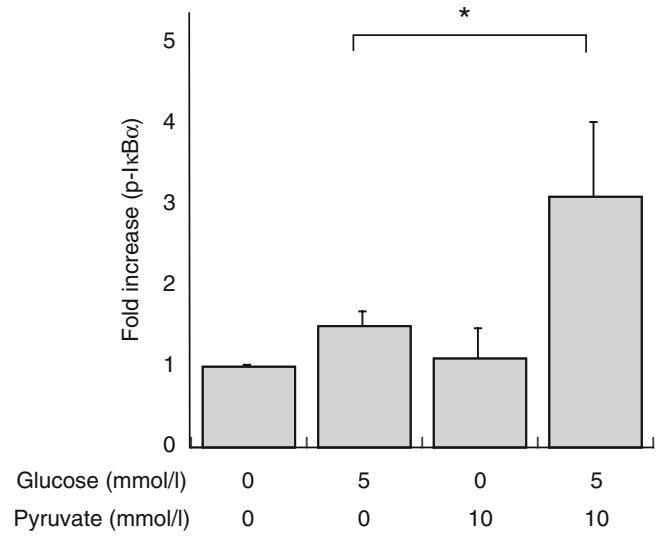

Fig. 7 Effect of pyruvate on phospho-IкB $\alpha(\mathrm{p}-\mathrm{I} \kappa \mathrm{B} \alpha)$, a reflection of IKK $\beta$ activity, in the absence and presence of $5 \mathrm{mmol} / 1$ glucose. Western blots of phospho-IкB $\alpha$ were performed on extracts of HMEC that were cultured for the denoted time in the presence of various concentrations of pyruvate and glucose. A two-tailed $t$ test was used to determine statistical significance of differences in mean values using Stata 8 (StataCorp, College Station, TX). ${ }^{*} p<0.05$, considered significant
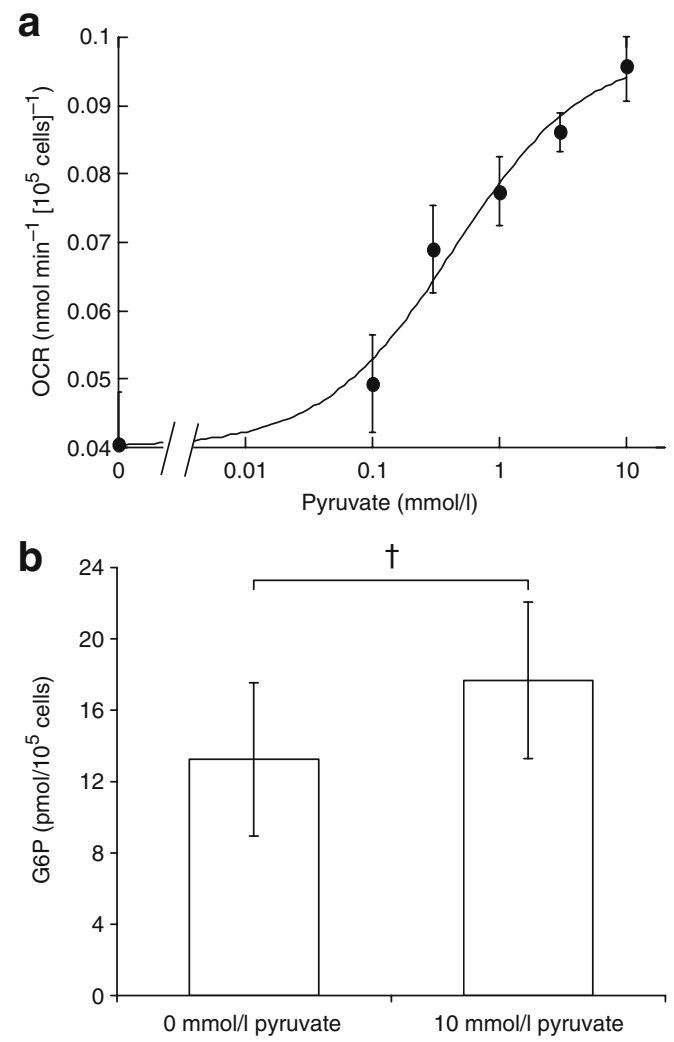

Fig. 8 Effect of pyruvate on OCR (a) and G6P (b) in the presence of $5 \mathrm{mmol} / \mathrm{l}$ glucose. Measurements are obtained as described in Fig. 5 except that each data point is an average of five separate experiments. Error bars are $\pm \mathrm{SEM} ;{ }^{\dagger} p=0.005$ calculated by a paired $t$ test using Kaleidagraph (Synergy Software, Reading, PA, USA)

to excess substrate correlates with accumulation of G6P but not with measures of mitochondrial respiration. These observations suggest that alternative metabolic pathways using G6P, such as the pentose phosphate shunt, cytoplasmic ROS generation (via NADPH oxidase) or hexosamine biosynthesis, are candidates for the glucose-sensing mechanism involved in $\mathrm{I} \kappa \mathrm{B} \alpha$ activation. The biochemical factors pertinent to these interpretations are now discussed.

Mechanisms governing the relationship between glucose use and glucose availability In muscle and fat, the rate of glucose uptake is controlled by both transport and phosphorylation of glucose. Control by the former dominates in the fasting state when insulin levels are low, while the latter dominates after a meal when insulin-stimulated glucose transport is increased by five- to tenfold [23]. Glucose transport in HMEC is mediated by GLUT1 [7] and is not insulin-sensitive [8]. Since the observed $K_{\mathrm{m}}$ for G6P in response to exogenous glucose was much greater (about $3.5 \mathrm{mmol} / \mathrm{l}$ ) than reported for HK I (approximately $0.05 \mathrm{mmol} / \mathrm{l})$, the $V_{\max }$ for glucose transport in HMEC is likely to be substantially lower than $\mathrm{HK}$, allowing the $K_{\mathrm{m}}$ for glucose transport to control the rate of glucose conversion 
Table 1 Relationship between changes in G6P and $\mathrm{I} \kappa \mathrm{B} \alpha$ activation, but not between changes in OCR and I $\mathrm{B} \alpha$ activation, in the presence of various concentrations of glucose and pyruvate

\begin{tabular}{|c|c|c|c|c|c|}
\hline Conditions & $\begin{array}{l}\text { Change in OCR } \\
\left(\mathrm{nmol} \min ^{-1}\left[10^{5} \text { cells }\right]^{-1}\right)\end{array}$ & $p$ value & $\begin{array}{l}\text { Change in G6P } \\
\left(\mathrm{pmol} / 10^{5} \text { cells }\right)\end{array}$ & $p$ value & $\begin{array}{l}\mathrm{I} \kappa \mathrm{B} \alpha \\
\text { activation }\end{array}$ \\
\hline No substrate & $0.028 \pm 0.008$ & $<0.02$ & -14.5 & $<0.001$ & No \\
\hline $\begin{array}{l}0 \mathrm{mmol} / 1 \text { glucose }+ \\
10 \mathrm{mmol} / 1 \text { pyruvate }\end{array}$ & $0.032 \pm 0.002$ & $<0.005$ & $>-14.5^{\mathrm{a}}$ & & No \\
\hline $\begin{array}{l}5 \mathrm{mmol} / 1 \text { glucose }+0 \mathrm{mmol} / 1 \\
\text { pyruvate }\end{array}$ & 0 & & 0 & & No \\
\hline $\begin{array}{l}5 \mathrm{mmol} / 1 \text { glucose }+ \\
10 \mathrm{mmol} / 1 \text { pyruvate }\end{array}$ & $0.055 \pm 0.008$ & $<0.005$ & $4.4 \pm 0.8$ & $<0.005$ & Yes \\
\hline $\begin{array}{l}25 \mathrm{mmol} / 1 \text { glucose }+ \\
0 \mathrm{mmol} / 1 \text { pyruvate }\end{array}$ & $-0.002 \pm 0.001$ & NS & $4.4 \pm 1.8$ & $<0.05$ & Yes \\
\hline
\end{tabular}

Data are means \pm SEM

Summary of measurements of G6P and steady-state OCR (from Figs 5, 6 and 8), and IкB $\alpha$ phosphorylation (from Figs 1 and 7 )

I $\mathrm{B} \alpha$ was considered to be activated if an increase of threefold or greater was observed. OCR and G6P results were normalised relative to values obtained at $5 \mathrm{mmol} / 1$ glucose

Paired $t$ tests were used to determine statistical significance of differences in group mean values using Kaleidagraph (Synergy Software, Reading, PA, USA)

${ }^{\mathrm{a}} \mathrm{G} 6 \mathrm{P}$ in the absence of glucose was below the detection limit of the assay $\left(<0.5 \mathrm{pmol} / 10^{5}\right.$ cells $)$ and since the increase of G6P in presence of $10 \mathrm{mmol} / \mathrm{l}$ pyruvate was not detectable with an $n=2$, no statistical analysis was performed

to G6P. Although glycogen breakdown may contribute to G6P levels, endothelial cells have low glycogen stores, and G6P is barely detectable in the absence of exogenous glucose. Somewhat unexpectedly, we observed that $\mathrm{NAD}(\mathrm{P}) \mathrm{H}$, lactate and OCR responses are unchanged at glucose concentrations $>5 \mathrm{mmol} / \mathrm{l}$. The robust increase of OCR that we observed with media containing pyruvate in addition to $5 \mathrm{mmol} / \mathrm{l}$ glucose, indicated that the TCA cycle is not saturated at $5 \mathrm{mmol} / \mathrm{l}$ glucose. Rather, metabolic flux during hyperglycaemia appears to be constrained by a rate-limiting step in glycolysis distal to G6P, perhaps involving inhibition of PFK, which converts G6P to fructose 6-phosphate (F6P).

G6P as a signal of cellular energy state The accumulation of G6P during incubation of endothelial cells in supraphysiological glucose suggests that downstream metabolic steps are rate-limiting. The similar response observed with the addition of pyruvate, a respiratory substrate, to media containing physiological glucose concentrations could be explained by feedback inhibition of PFK, which is a known consequence of increased energy state (ATP/ADP) from substrate-driven ADP phosphorylation [24]. Pyruvate could also exert this effect by increasing levels of citrate, an allosteric inhibitor of PFK [25]. Inhibition of PFK would in turn lead to increased levels of the upstream intermediate, G6P. Increased ATP generated by excess substrate availability may also lead by mass action to glucose phosphorylation, overcoming inhibition of HK by G6P [26], and availability of glucose at concentrations that exceed metabolic requirements would lead to similar restriction of glycolytic flow. Since reduced PFK activity (high glucose or low glucose+ pyruvate) with or without increased HK flux (high glucose) favours accumulation of G6P, intracellular G6P concentration may constitute a cellular signal of excess glycolytic or mitochondrial substrate.

Previous reports have attributed increased intracellular F6P levels in $30 \mathrm{mmol} / \mathrm{l}$ glucose to inhibition of glyceraldehyde-3-phosphate dehydrogenase (GAPDH) $(66 \%$ decrease) [5]. However, the near-equilibrium state of the GAPDH reaction [27], combined with the 30 -fold overcapacity of GAPDH activity [28], suggests that the observed reduction of GAPDH activity would not significantly reduce glycolytic flux. Irrespectively, G6P and the other phosphorylated hexoses (glucose 1-phosphate and F6P) in equilibrium with G6P are at a metabolic crossroads, where the relative $K_{\mathrm{m}}$ and $V_{\max }$ of PFK, G6P dehydrogenase, glycogen synthase and glutamine:F6P amidotransferase (GFAT) determine their metabolic fates. Therefore, changes in G6P are strategically positioned to link cellular energy state with regulation of multiple functions of the cell.

Coupling energy state to pro-inflammatory response by G6P The observation of coincident increases of G6P concentration and phospho-IкB $\alpha$ in response to excess metabolic substrates raises the possibility that inflammatory $\operatorname{I\kappa B} \alpha /$ $\mathrm{NF}-\mathrm{\kappa B}$ signalling is regulated by one of several nonglycolytic pathways using G6P. One candidate is the hexosamine biosynthesis pathway that ultimately affects cellular function via post-translational modification of proteins by O-glycosylation [29, 30]. In most cell types, F6P and G6P 
exist in an equilibrium ratio of 0.27 [31]. So assuming that $10^{5}$ cells contain about $0.08 \mu \mathrm{l}$, it can be estimated that the concentration of G6P in HMEC cells at $25 \mathrm{mmol} / 1$ glucose $=$ $25 \mathrm{pmol} / 0.08 \mu \mathrm{l}$ or $300 \mu \mathrm{mol} / \mathrm{l}$, and so F6P is approximately $85 \mu \mathrm{mol} / \mathrm{l}$. GFAT regulates the flux control step from F6P in the hexosamine biosynthesis pathway. Since the $K_{\mathrm{m}}$ of F6P substrate for GFAT is $0.2-1.0 \mathrm{mmol} / 1$ [32], the concentration of intracellular F6P is well below GFAT saturation, and changes in G6P and F6P pools will translate linearly into changes in flux through the hexosamine biosynthesis pathway. As hexosamine biosynthesis has been associated with vascular inflammation [33], changes in G6P produced by excess substrate could act as a driving force.

It was previously reported for bovine endothelial cells that the pentose phosphate shunt is a greater source of $\mathrm{CO}_{2}$ than the TCA cycle [12]. The greater sensitivity of $\mathrm{CO}_{2}$ production and G6P levels to hyperglycaemia relative to OCR are consistent with increased pentose phosphate shunt activity. Plasma membrane NADPH-dependent oxidase has been reported as a source of ROS in high-glucose conditions $[34,35]$. Thus our data suggest that the pentose phosphate shunt could supply cytosolic NADPH [36] to NADPH-dependent oxidase, resulting in a rate of generation of ROS in the cytosol that would increase during hyperglycaemia.

Unique sensing of substrate by cells exhibiting the Crabtree effect Endothelial cells exhibit a paradoxical decrease of OCR in response to glucose concentrations $>0.1 \mathrm{mmol} / \mathrm{l}$, a phenomenon known as the Crabtree effect [37]. Although often described as a unique characteristic of tumour cells [38], it appears that many proliferative cell types [39], including lymphocytes [40], fibroblasts (M. Gilbert and I. Sweet, unpublished observations) and endothelial cells [41] display this phenomenon in cell culture. Since deleterious effects of hyperglycaemia have also been noted for each of these cell types, the importance of this mode of metabolic regulation for glucotoxicity warrants further study. We speculate that the dependency of adverse responses to excess glucose on G6P, but not NADH or OCR, may be a general characteristic of cells that display Crabtree behaviour.

The hallmark of cells displaying the Crabtree effect is a high rate of glycolytic ATP generation relative to mitochondrial ATP production [42]. Interestingly, this only occurred at concentrations $>0.1 \mathrm{mmol} / 1$ glucose, perhaps because the effect does not occur until the energy demands of the cell are met. At physiological levels of glucose, glycolytic production of ATP is substantial and the rate of electron transport (OCR) and mitochondrial ATP synthesis in these cells are strongly inhibited. As a consequence of the increased contribution of glycolysis to cellular phosphorylation potential (ATP/ADP/inorganic phosphate), the main driving force for mitochondrial electron transport and oxidative phosphorylation is reduced [43]. These considerations are at odds with evidence from other cell types that mitochondrial generation of ROS increases in high-glucose media [44-46]. Mitochondrial ROS generation occurs by transfer of electrons directly to molecular oxygen at complex 1 and 3 of the electron transport chain [47], and is often associated with increased oxidation of mitochondrial fuels. The operation of the Crabtree effect would appear to minimise the contribution of ROS by this mechanism and favour the contributions from other aspects of cellular glucose metabolism [48, 49], including via increased NADPH oxidase activity.

Summary Inflammatory signalling via the IKK $\beta-\mathrm{NF}-\mathrm{\kappa B}$ pathway is induced in endothelial cells within minutes of exposure to excess metabolic substrate, and occurs despite a paradoxical decrease of oxidative mitochondrial metabolism known as the Crabtree effect. This metabolic response is observed in a variety of proliferating cell types that are susceptible to glucose-induced inflammation and cytotoxicity. Whereas a large literature implicates mitochondrial ROS generation in the pathogenesis of cellular glucotoxicity, our findings suggest non-glycolytic use of G6P as a candidate mediator of this effect in human endothelial cells. Potential mechanisms whereby increased levels of G6P could contribute to glucotoxicity include increased flux through the hexosamine biosynthesis pathway and/or the pentose phosphate shunt, or increased ROS generation involving cytoplasmic NADPH oxidase. Clarifying possible G6P-dependent mechanisms for IкB $\alpha$ activation, and examining whether pro-inflammatory signalling by excess glucose supply is a general feature of cells exhibiting a Crabtree effect, is an important priority for future work. At present, the implications of the study are limited to the canonical activation of NF- $\kappa \mathrm{B}$ by I $\kappa \mathrm{B} \alpha$ phosphorylation, whereas it has been shown that alternative pathways of $\mathrm{NF}-\kappa \mathrm{B}$ activation exist, such as through IкB $\beta$ phosphorylation [50]. In addition, we cannot rule out the possibility that the relationship between G6P and NF- $\mathrm{KB}$ activation is only correlative and not causal.

Acknowledgements This research was funded by grants from the National Institutes of Health (U54 CA116847, TE 4038, DK073878, DK17047, DK068384 and DK063986) and the National Science Foundation (SBIR IIP-0750508).

Duality of interest The authors declare that there is no duality of interest associated with this manuscript.

\section{References}

1. Kim F, Pham M, Luttrell I et al (2007) Toll-like receptor-4 mediates vascular inflammation and insulin resistance in dietinduced obesity. Circ Res 100:1589-1596 
2. Kim F, Tysseling KA, Rice J et al (2005) Activation of IKKbeta by glucose is necessary and sufficient to impair insulin signaling and nitric oxide production in endothelial cells. J Mol Cell Cardiol 39:327-334

3. Du XL, Edelstein D, Dimmeler S, Ju Q, Sui C, Brownlee M (2001) Hyperglycemia inhibits endothelial nitric oxide synthase activity by posttranslational modification at the Akt site. J Clin Invest 108:1341-1348

4. Federici M, Menghini R, Mauriello A et al (2002) Insulindependent activation of endothelial nitric oxide synthase is impaired by O-linked glycosylation modification of signaling proteins in human coronary endothelial cells. Circulation 106: 466-472

5. Du XL, Edelstein D, Rossetti L et al (2000) Hyperglycemiainduced mitochondrial superoxide overproduction activates the hexosamine pathway and induces plasminogen activator inhibitor-1 expression by increasing Sp1 glycosylation. Proc Natl Acad Sci U S A 97:12222-12226

6. Hacker H, Karin M (2006) Regulation and function of IKK and IKK-related kinases. Sci STKE 2006:re13

7. Watson RT, Pessin JE (2001) Intracellular organization of insulin signaling and GLUT4 translocation. Recent Prog Horm Res 56:175-193

8. Artwohl M, Brunmair B, Furnsinn C et al (2007) Insulin does not regulate glucose transport and metabolism in human endothelium. Eur J Clin Invest 37:643-650

9. Vinals F, Gross A, Testar X, Palacin M, Rosen P, Zorzano A (1999) High glucose concentrations inhibit glucose phosphorylation, but not glucose transport, in human endothelial cells. Biochim Biophys Acta 1450:119-129

10. Wilson JE (2003) Isozymes of mammalian hexokinase: structure, subcellular localization and metabolic function. J Exp Biol 206:2049-2057

11. Carruthers A (1990) Facilitated diffusion of glucose. Physiol Rev 70:1135-1176

12. Dobrina A, Rossi F (1983) Metabolic properties of freshly isolated bovine endothelial cells. Biochim Biophys Acta 762:295-301

13. Sweet IR, Gilbert M (2006) Contribution of calcium influx in mediating glucose-stimulated oxygen consumption in pancreatic islets. Diabetes 55:3509-3519

14. Karin M (1999) How NF-kappaB is activated: the role of the IkappaB kinase (IKK) complex. Oncogene 18:6867-6874

15. Sweet IR, Cook DL, DeJulio E et al (2004) Regulation of ATP/ ADP in pancreatic islets. Diabetes 53:401-409

16. Sweet IR, Cook DL, Wiseman RW et al (2002) Dynamic perifusion to maintain and assess isolated pancreatic islets. Diabetes Technol Ther 4:67-76

17. Sweet IR, Khalil G, Wallen AR et al (2002) Continuous measurement of oxygen consumption by pancreatic islets. Diabetes Technol Ther 4:661-672

18. Wilson DF, Owen CS, Holian A (1977) Control of mitochondrial respiration: a quantitative evaluation of the roles of cytochrome $\mathrm{c}$ and oxygen. Arch Biochem Biophys 182:749-762

19. Sweet IR, Li G, Najafi H, Berner D, Matschinsky FM (1996) Effect of a glucokinase inhibitor on energy production and insulin release in pancreatic islets. Am J Physiol 271:E606-E625

20. Sweet IR, Najafi H, Li G, Grodberg J, Matschinsky FM (1997) Measurement and modeling of glucose-6-phosphatase in pancreatic islets. Am J Physiol 272:E696-E711

21. Lowry O, Passonneau J (1972) A flexible system of enzymatic analysis. Academic, New York

22. Sola MM, Oliver FJ, Salto R, Gutierrez M, Vargas A (1994) Citrate inhibition of rat-kidney cortex phosphofructokinase. Mol Cell Biochem 135:123-128

23. Fueger PT (2005) Glucose phosphorylation as a barrier to muscle glucose uptake. Clin Exp Pharmacol Physiol 32:314-318
24. Pettigrew DW, Frieden C (1979) Rabbit muscle phosphofructokinase. A model for regulatory kinetic behavior. J Biol Chem 254:1896-1901

25. Garland PB, Randle PJ, Newsholme EA (1963) Citrate as an intermediary in the inhibition of phosphofructokinase in rat heart muscle by fatty acids, ketone bodies, pyruvate, diabetes, and starvation. Nature 200:169-170

26. Randle PJ, Newsholme EA, Garland PB (1964) Regulation of glucose uptake by muscle. 8. Effects of fatty acids, ketone bodies and pyruvate, and of alloxan-diabetes and starvation, on the uptake and metabolic fate of glucose in rat heart and diaphragm muscles. Biochem J 93:652-665

27. Schulz J, Baufeld A, Hofmann E, Rapoport TA, Heinrich R, Rapoport SM (1977) Regulation of anaerobic glycolysis in Ehrlich ascites tumour cells. Acta Biol Med Ger 36:1379-1391

28. Newsholme E, Start C (1973) Regulation in metabolism. Wiley, London

29. Akimoto Y, Hart GW, Hirano H, Kawakami H (2005) O-GlcNAc modification of nucleocytoplasmic proteins and diabetes. Med Mol Morphol 38:84-91

30. Chatham JC, Not LG, Fulop N, Marchase RB (2008) Hexosamine biosynthesis and protein O-glycosylation: the first line of defense against stress, ischemia, and trauma. Shock 29:431-440

31. Greenbaum AL, Gumaa KA, McLean P (1971) The distribution of hepatic metabolites and the control of the pathways of carbohydrate metabolism in animals of different dietary and hormonal status. Arch Biochem Biophys 143:617-663

32. Broschat KO, Gorka C, Page JD et al (2002) Kinetic characterization of human glutamine-fructose-6-phosphate amidotransferase I: potent feedback inhibition by glucosamine 6-phosphate. J Biol Chem 277:14764-14770

33. Xu Y, He Z, King GL (2005) Introduction of hyperglycemia and dyslipidemia in the pathogenesis of diabetic vascular complications. Curr Diab Rep 5:91-97

34. Inoguchi T, Sonta T, Tsubouchi H et al (2003) Protein kinase Cdependent increase in reactive oxygen species (ROS) production in vascular tissues of diabetes: role of vascular NAD $(\mathrm{P}) \mathrm{H}$ oxidase. J Am Soc Nephrol 14:S227-S232

35. Griendling KK, Sorescu D, Ushio-Fukai M (2000) NAD(P)H oxidase: role in cardiovascular biology and disease. Circ Res 86:494-501

36. Spolarics Z (1998) Endotoxemia, pentose cycle, and the oxidant/ antioxidant balance in the hepatic sinusoid. J Leukoc Biol 63:534541

37. Crabtree HG (1929) Observations on carbohydrate metabolism of tumors. Biochem J 23:536-545

38. Krebs HA (1972) The Pasteur effect and the relations between respiration and fermentation. Essays Biochem 8:1-34

39. Ibsen KH (1961) The Crabtree effect: a review. Cancer Res 21:829-841

40. Guppy M, Greiner E, Brand K (1993) The role of the Crabtree effect and an endogenous fuel in the energy metabolism of resting and proliferating thymocytes. Eur J Biochem 212:95-99

41. Krutzfeldt A, Spahr R, Mertens S, Siegmund B, Piper HM (1990) Metabolism of exogenous substrates by coronary endothelial cells in culture. J Mol Cell Cardiol 22:1393-1404

42. Koobs DH (1972) Phosphate mediation of the Crabtree and Pasteur effects. Science 178:127-133

43. Sussman I, Erecinska M, Wilson DF (1980) Regulation of cellular energy metabolism: the Crabtree effect. Biochim Biophys Acta 591:209-223

44. Nishikawa T, Araki E (2007) Impact of mitochondrial ROS production in the pathogenesis of diabetes mellitus and its complications. Antioxid Redox Signal 9:343-353

45. Piconi L, Quagliaro L, Assaloni R et al (2006) Constant and intermittent high glucose enhances endothelial cell apoptosis through mitochondrial superoxide overproduction. Diabetes Metab Res Rev 22:198-203 
46. Lin Y, Berg AH, Iyengar P et al (2005) The hyperglycemiainduced inflammatory response in adipocytes: the role of reactive oxygen species. J Biol Chem 280:4617-4626

47. Turrens JF (2003) Mitochondrial formation of reactive oxygen species. J Physiol 552:335-344

48. Boveris A, Chance B (1973) The mitochondrial generation of hydrogen peroxide. General properties and effect of hyperbaric oxygen. Biochem J 134:707-716
49. Korshunov SS, Skulachev VP, Starkov AA (1997) High protonic potential actuates a mechanism of production of reactive oxygen species in mitochondria. FEBS Lett 416:1518

50. Biswas G, Tang W, Sondheimer N, Guha M, Bansal S, Avadhani NG (2008) A distinctive physiological role for IkappaBbeta in the propagation of mitochondrial respiratory stress signaling. J Biol Chem 283:12586-12594 